\title{
Translation, Psycho-Properties Test and Cultural Adaptation of Depression Literacy Questionnaire in China
}

\author{
Weiren Wang, Yanqiong Ouyang* \\ School of Health Sciences, Wuhan University, Wuhan, China \\ Email: *ouyangyq@whu.edu.cn
}

How to cite this paper: Wang, W. R., \& Ouyang, Y. Q. (2019). Translation, Psycho-Properties Test and Cultural Adaptation of Depression Literacy Questionnaire in China. Open Journal of Depression, 8 , 48-57.

https://doi.org/10.4236/ojd.2019.82006

Received: February 26, 2019

Accepted: April 14, 2019

Published: April 17, 2019

Copyright ( 2019 by author(s) and Scientific Research Publishing Inc. This work is licensed under the Creative Commons Attribution International License (CC BY 4.0).

http://creativecommons.org/licenses/by/4.0/

\section{Open Access}

\begin{abstract}
Background: Depressive disorder is a serious and common problem among adolescents and young adults in China, as they are engaged in an important period of psychological development. It is necessary to make an accessible tool to measure their knowledge situation towards depression. Methods: 461 respondents from two schools were recruited in this study from September 2017 to March 2018. Internal consistence, factor analysis and content validity index (CVI) were used to evaluate the reliability and validity of Chinese version Depression Literacy Questionnaire. Results: The Cronbach's $\alpha$ of 0.885 revealed good internal consistency of the reliability. The CVI of 0.989 and the EFA reflected good validity of D-Lit. Conclusions: The Chinese version D-Lit was proved reliable and valid among Chinese adolescence and young adults to assess status of knowledge towards DD.
\end{abstract}

\section{Keywords}

Depression, Literacy, Knowledge, Chinese, Translation, Cultural Adaptation

\section{Introduction}

Depressive disorder (DD) is a common mental illness, which may have serious effects on both individual and public health. DD is characterized by a persistent depressed mood, loss of interest or pleasure, loss of words and actions, and other physical symptoms. It can cause the affected person to suffer greatly and function poorly at work, at school and in the family. At its worst, depression can lead to suicide (World Health Organization, 2017).

DD has high rates of prevalence, relapse, mortality, and suicide. A 2017 World Health Organization report shows 322 million people are suffering from DD at 
present, equivalent to over $4 \%$ of the world's population. DD is the leading cause of disability all over the world, and is a major contributor to the overall global burden of disease (World Health Organization, 2017).

Despite the fact that effective and systemic intervention and treatment can relieve symptoms of $\mathrm{DD}$, the poor awareness and recognition of depression result in the phenomenon that only a small percentage of patients would like to seek for professional help on their own initiative. Only $12.4 \%$ of college students showed their willingness to seek professional help (Seyfi et al., 2013). Data from Ministry of Education of the People's Republic of China showed that about four-fifths college students chose their intimate friends or peers as their only or the most preferred resource before seeking professional help due to psychological problems (Huang et al., 2011), and their peers and friends might lack of mental health related knowledge as well. This phenomenon acts as a barrier for students with psycho-problems to seek professional help conversely.

DD is a particular concern in older adolescents to young adults, a key stage of students' psychological development and a high-risk time for mental health problems (Bee, 2008). The first peak of onset of DD has been reported at 18 years old (Hankin et al., 1998). A national comorbidity survey (National Comorbidity Survey-R., 2007) in the United States (U.S.) found that the lifetime prevalence of major depressive disorder (MDD) and dysthymia between 18 - 29 years old was $17.8 \%$. In China, a study found that $29.7 \%$ of college students had mild-to-moderate depressive symptoms (Xu et al., 2016).

Thus, it is important to know the knowledge and perceptions related to DD among young adults and adolescents. However, there was no accessible instrument to measure the depression knowledge in China. A systematic review of 17 studies (Wei et al., 2016) revealed 16 tools to assess knowledge and public perception towards mental health. As for depression, the Depression Literacy Questionnaire (D-lit) is a reliable and valid tool used to evaluate depression related knowledge. To date, D-Lit has been translated and validated in multiple languages (Jeong et al., 2017; Arafat et al., 2017; Ahmed et al., 2016; Kiropoulos et al., 2011; Griffiths et al., 2004). However, no Chinese version has been translated and validated for all we know.

The purpose of this study is to translate the English version of Depression Literacy Questionnaire into Chinese, and to do psycho-properties test of its Chinese version among the college students after the cultural adaption, so that it can be used in the Chinese adolescents and young adults. Reliability and validity were tested to prove its accessibility.

\section{Methodology}

\subsection{The Depression Literacy Questionnaire}

The Depression Literacy Questionnaire is a 22-item questionnaire designed for assessing the participant's knowledge about signs and treatments for depression by Griffiths et al. (2004). Each item is set with "True", "False" and "Don't know" 
choices with only one right answer. Respondents will be given 1 point for each correct response, and get a continuous score from 0 to 22 totally. The higher points equal to the better knowledge status towards depression.

\subsection{Participants and Data Collection}

The samples were chosen from two universities from Hubei Province and Heilongjiang Province in China, including one comprehensive university and one medical university. According to the rules of sampling, the sample size was calculated to be 220 (Sun \& Xu, 2014). Assuming 10\% attrition, 245 students were recruited in each school, totally 490 pieces of data were distributed.

Data collection took place from September 2017 to March 2018. The inclusion criteria of the test subjects were the students: 1) over 16 years old, 2) in the junior college or the school of a higher level, and 3) willing to participate in this survey. The exclusion criteria were the students: 1) affected by mental disorders, or 2) with a history of hospitalization for mental disorders.

461 pieces of effective data were recovered, with an effective data rate of $94.08 \%$. The mean age of the participants was 18.58 years old, and $62.25 \%$ of them were female.

\subsection{Translation and Cultural Adaptation}

The translation and cultural adaptation process of the D-Lit was guided by the World Health Organization (2015) translation guidelines, with the modifying cycle of forward translation; expert panel; back translation; pre-testing as well as interviewing and final version.

Initially, the literature review which showed that the D-Lit had not been translated and validated in China so far had been done. Then, the authorization for usage and translation of the D-Lit had been obtained from the original author before the study started.

Forward-translation of D-lit from English to Chinese was operated by two linguists majoring in English to get the initial CD-Lit\#1. The requirements in this process were: to make it conceptual equivalent; to make the expression simple, common and understandable; to avoid using professional terms; to consider respondent's age and gender and to avoid offensive words toward patients with depressive disorder.

Expert panel consisted of five experts, including one psychology teacher who was familiar with revision of scale, one psychiatric doctor, one mental health nurse, one psychotherapist and one psychological consultant. The CD-Lit\#1 was checked and modified by language, concept consistency and cultural adaption under the expert panel in conjunction with the former forward-translators to form the CD-Lit\#2. When it came to the inconformity, original author was contacted.

In the back translation process, under the same requirements as forward-translation, the CD-Lit\#2 was translated from Chinese to English by two bilingual English professors with no experience of the D-Lit before. The 
back-translation versions were sent back to the original author until reaching a consensus. The CD-Lit\#3 was an outcome in this stage.

The pre-testing and the interviewing were carried out among 10 participants, covering college students in different grades and majors. Interviewing was a semi-structured interviewing after they had accomplished the D-lit with the questions:

1) Can you tell us how do you find this questionnaire while you are fulfilling it, please?

2) Can you please tell us whether the expression of this questionnaire is clear?

3) Do you have any comments on how we can get this questionnaire improved?

4) Do you have any comments about this interview?

Then, the records of this process were sent to the original author to get the questionnaire revised. The final version of the CD-Lit was the consequence of all the iterations described above.

\subsection{Data Analysis}

Statistical Package for Social Sciences (SPSS 21.0 for Windows) was used to analyze the data in this study. Significance level was set to be 0.05 (two-tailed).

Demographic data were analyzed by descriptive statistical analysis. Categorical variables (gender, grade) were analyzed using frequency and percentage, while quantitative data (age) were analyzed using mean and standard deviations. The psychometric test comprised reliability and validity test. The former one in this study was presented by Cronbach's alpha coefficient, while the latter one by the value of content validity index (CVI) and factor analysis.

\subsection{Ethical Considerations}

The study proposal was approved by the Ethical Committee of Medical Division of Wuhan University. Authorization of the Depression Literacy Questionnaire was granted from the original author. The whole process of the study was anonymous and voluntary for respondents. Before filling in the questionnaire, participants were asked to sign on the consent form after reading it, including the explanation of the study, what they should do and the permission of withdrawal at any time.

\section{Results}

\subsection{Demographic Characteristics of the Participants}

A total of 461 respondents from two schools finished the survey completely, and their socio-demographic characteristics (gender, department, grade) were shown in Table 1. The mean age of the participants was 18.58 years old $(\mathrm{SD}=1.19)$.

\subsection{Reliability Test of the Chinese Version D-Lit}

Cronbach's alpha coefficient, a typical index for measuring internal consistency, 
Table 1. Socio-demographic characteristics of the students $(\mathrm{N}=461)$.

\begin{tabular}{ccc}
\hline Characteristic & Frequency $(\mathrm{n})$ & Percentage $(\%)$ \\
\hline Gender & 174 & 37.74 \\
male & 287 & 62.26 \\
female & & \\
Department & 212 & 45.99 \\
medical & 134 & 29.07 \\
science and engineering & 69 & 14.97 \\
economy and management & 46 & 9.98 \\
others & & \\
Grade & 210 & 45.55 \\
one & 95 & 20.61 \\
two & 94 & 20.39 \\
three & 62 & 13.45 \\
four & 461 & 100 \\
Total & &
\end{tabular}

was used in this study to assess the reliability of the Chinese version D-Lit. The overall value was equal to 0.885 . A Cronbach's alpha coefficient value of beyond 0.7 is significant. The specific evaluation criteria are as follows (Zhao, 2014): 0.6 $=$ acceptable, $0.6-0.65=$ not good enough, $0.65-0.7=$ the minimum acceptable degree, $0.7-0.8=$ good, $0.8-0.9=$ very good, much higher than $0.9=$ should be considered to shorten the scale.

The result of 0.885 proved that the internal consistency of the Chinese version of D-Lit was very good.

\subsection{Validity Test of the Chinese Version D-Lit}

Validity is a most important indicator for a scale, reflecting whether a tool can measure the degree of target accurately, including content-related validity, construct-related validity, criterion-related validity, etc. The more consistent the results are with the aimed investigating target, the higher the validity will be. On the contrary, the validity is lower.

\subsubsection{Content Validity Index, CVI}

CVI is a common indicator representing content-related validity. 3 psychiatrists and 3 psychologists were invited to evaluate the content validity of the Chinese version D-Lit. They were asked to mark each item of the Chinese version D-Lit, from " 1 = No correlation, 2 = Low correlation, 3 = Correlation, $4=$ Strong correlation". The content validity of the total questionnaire was 0.989 . A mean CVI value of 0.8 or more by over 5 professionals is significant (Zhao, 2014).

\subsubsection{Factor Analysis}

Construct validity can be measured by exploratory factor analysis and confir- 
matory factor analysis. Exploratory factor analysis was used in this study.

Kaiser-Meyer-Olkin (KMO) Measure and Bartlett's test for sphericity were found to be 0.885 , which suggested highly significant $(P<0.001)$. Factor analysis and extraction showed commonalities (Table 2) of all item were 0.3 or above, indicating its feasibility (Tabachnick \& Fidell, 2007). Only one single factor was selected, as the result of the scree plot (Figure 1). And based on the original English version of D-Lit, one factor could explain all the items.

\subsection{The Scores of the Chinese Version D-Lit}

Descriptive analysis of the Chinese Version D-Lit was done for this study. The mean score of knowledge among the respondents was $11.11 \pm 3.64$, and median was 11. As was shown in Table 3, accuracy of item 2, 4, 9, 11, 13, 14, 15, 22 were above $60 \%$, while 40 to 60 percent of the participants made a correct answer on item $1,3,5,7,8,12,19,20$. The items mentioned above got fairish correct rate among this population. However, others reflected different understandings detailly. For instance, less than $7 \%$ respondents knew that antidepressants were the

Table 2. Results of factor analysis.

\begin{tabular}{|c|c|c|c|}
\hline & Item to Total Correlation & Factor-loading & Communalities \\
\hline Q1 & 0.214 & 0.553 & 0.432 \\
\hline Q2 & 0.378 & 0.567 & 0.424 \\
\hline Q3 & 0.210 & 0.607 & 0.369 \\
\hline Q4 & 0.356 & 0.607 & 0.462 \\
\hline Q5 & 0.311 & 0.380 & 0.400 \\
\hline Q6 & 0.277 & 0.535 & 0.406 \\
\hline Q7 & 0.500 & 0.652 & 0.595 \\
\hline Q8 & 0.484 & 0.752 & 0.649 \\
\hline Q9 & 0.367 & 0.376 & 0.296 \\
\hline Q10 & 0.235 & 0.383 & 0.356 \\
\hline Q11 & 0.419 & 0.573 & 0.480 \\
\hline Q12 & 0.246 & 0.388 & 0.523 \\
\hline Q13 & 0.508 & 0.642 & 0.533 \\
\hline Q14 & 0.288 & 0.323 & 0.347 \\
\hline Q15 & 0.399 & 0.743 & 0.616 \\
\hline Q16 & 0.293 & 0.465 & 0.415 \\
\hline Q17 & 0.286 & 0.618 & 0.522 \\
\hline Q18 & 0.413 & 0.701 & 0.553 \\
\hline Q19 & 0.381 & 0.669 & 0.495 \\
\hline Q20 & 0.365 & 0.477 & 0.437 \\
\hline Q21 & 0.332 & 0.482 & 0.452 \\
\hline Q22 & 0.428 & 0.539 & 0.409 \\
\hline
\end{tabular}


Table 3. The accuracy of the Chinese version D-Lit.

\begin{tabular}{|c|c|c|}
\hline Item & Correct number (n) & Correct rate $(\%)$ \\
\hline 1 & 238 & 51.6 \\
\hline 2 & 379 & 82.2 \\
\hline 3 & 215 & 46.6 \\
\hline 4 & 380 & 82.4 \\
\hline 5 & 188 & 40.8 \\
\hline 6 & 102 & 22.1 \\
\hline 7 & 249 & 54 \\
\hline 8 & 206 & 44.7 \\
\hline 9 & 330 & 71.6 \\
\hline 10 & 154 & 33.4 \\
\hline 11 & 315 & 68.3 \\
\hline 12 & 217 & 47.1 \\
\hline 13 & 312 & 67.7 \\
\hline 14 & 293 & 63.6 \\
\hline 15 & 381 & 82.6 \\
\hline 16 & 32 & 6.9 \\
\hline 17 & 121 & 26.2 \\
\hline 18 & 150 & 32.5 \\
\hline 19 & 195 & 42.3 \\
\hline 20 & 227 & 49.2 \\
\hline 21 & 80 & 17.4 \\
\hline 22 & 357 & 77.4 \\
\hline
\end{tabular}

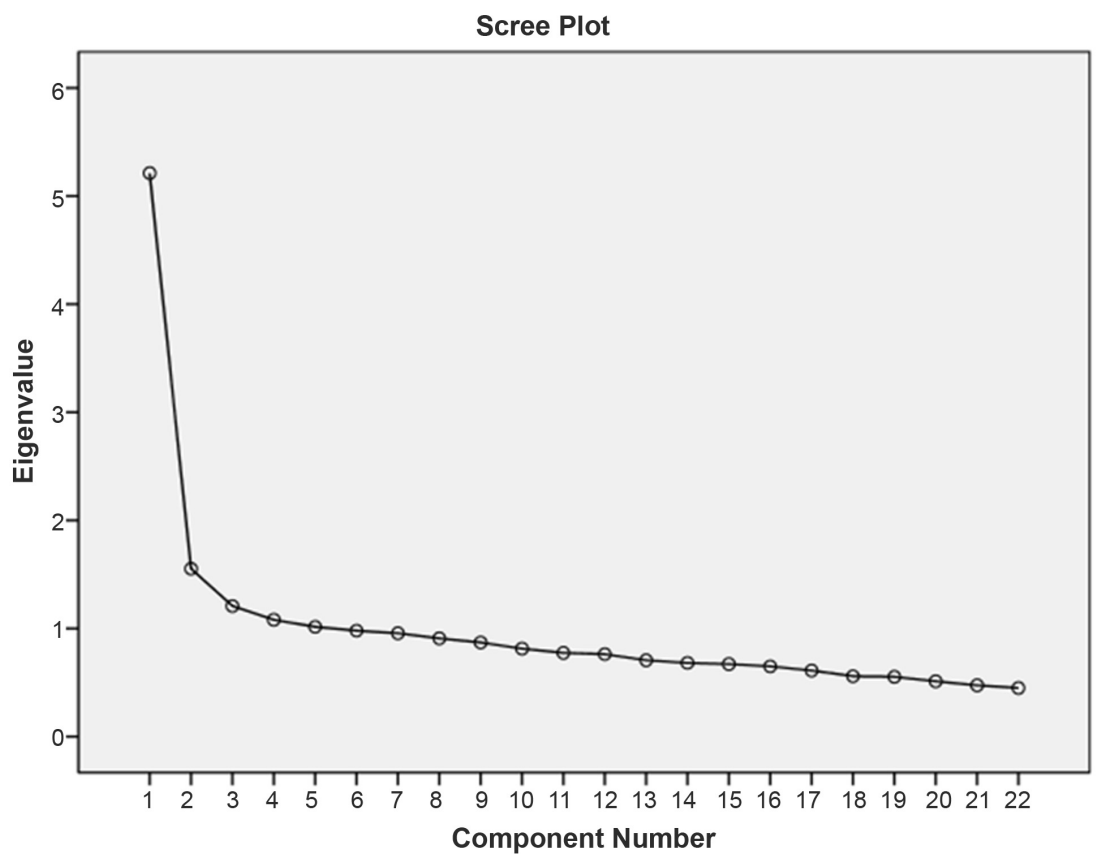

Figure 1. Scree plot of the factor analysis of the Chinese D-Lit. 
most effective treatment for depression (item 16). Item 21 revealed that most individuals $(82.6 \%)$ had misunderstanding of the addiction of the antidepressants. Only 22.1 percent of participants were aware of that the fact auditory hallucination was not a common symptom of depression, but schizophrenia (item 6) (Carpenter et al., 1974). The results also inferred that some people were prone to confuse depression disorder with schizophrenia, obsessive-compulsive disorder, mania and other mental disorders, and had little understanding of the treatment of depression, the use of antidepressants, or the working permission of psychotherapists (American Psychiatric Association, 2013).

\section{Discussion}

\subsection{Implementation and Significance of the Chinese Version D-Lit}

It is reported that Chinese adolescents are lack of knowledge regarding depression, which may lead to the stigma and a decline of help-seeking (Amarasuriya et al., 2018; Amarasuriya et al., 2015). This study translated, cultural adapted, and tested psychometric of English version of Depression Literacy Questionnaire into Chinese in order to understand the current situation of depression knowledge among young adults and adolescents, thus making a guidance and implementing the targeted intervention. The translation process of the measuring tool followed the scale development procedures strictly. It is a highly qualified and operable tool as the fact that it is simple to read and easy to score. Psychiatrists, mental health nurses, public health and mental health workers can use the D-Lit to obtain knowledge about the depression-related conditions of the aimed population and provide targeted health education, guidance and other relevant interventions.

\subsection{Psychometric Test of the Chinese Version D-Lit}

Depression Literacy Questionnaire (D-lit) was developed by K. M. Griffiths et al. and had been translated into several languages without Chinese. The Cronbach's alpha of D-Lit original (English) version, Greek version, Italian version, Arabic version and Bangla version was found $0.70,0.88,0.92,0.78$ and 0.77 respectively while the Spearman rho was found 0.91 in these studies (Arafat et al., 2017; Ahmed et al., 2016; Kiropoulos et al., 2011; Griffiths et al., 2004), which showed that the D-Lit was valid and reliable to be used in other cultures.

Internal consistency of the Chinese version of D-Lit was very good, with the value of Cronbach's alpha coefficient of 0.885 . 14 items got a 0.3 or above item-total correlation coefficient, and the other 8 items more than 0.2 . The original version questionnaire did not mention this (Griffiths et al., 2004), but the results of our study were similar to Arabic's (Ahmed et al., 2016). Results of factor analysis proved all of 22 items could be explained by one single factor so that Chinese version D-Lit could be valid as a measuring tool. Other studies had the same findings that the D-Lit was a unifactorial structure measuring tool (Arafat et al., 2017; Gulliver et al., 2012). 


\section{Conclusion}

There is a good reliability and validity of the Chinese version of Depression Literacy Questionnaire, and it can be used to evaluate knowledge regarding depression among Chinese adolescents and young adults.

\section{Limitations}

There are some limitations in this study:

1) Convenience sampling was used in this study, leading to an unbalanced distribution of gender and grades. Female and grade one students took the predominate parts among all respondents, which might have limited generalizability.

2) Respondents were recruited voluntarily. People with high level of stigma towards depression or affected by depression may be loath to participate, which could be another sampling bias in this study.

3) Internal consistency was the only method to test reliability of the measuring tool, without test-retest, ignoring the bias due to different conditions, such as environment, etc.

\section{Conflicts of Interest}

The authors declare that there are no conflicts of interest in this study.

\section{References}

Ahmed, D. H., Salih, M. M., Mohamed, A. S. R., Mohammed, B., Abdullah, S., Abdulrahman, A. R., \& Hussain, M. (2016). Arabic Translation and Psychometric Evaluation of the Depression Literacy Questionnaire among Adolescents. Psychiatry Journal, 2016, Article ID: 8045262. https://doi.org/10.1155/2016/8045262

Amarasuriya, S. D., Jorm, A. F., \& Reavley, N. J. (2015). Depression Literacy of Undergraduates in a Non-Western Developing Context: The Case of Sri Lanka. BMC Research Notes, 8, 593. https://doi.org/10.1186/s13104-015-1589-7

Amarasuriya, S. D., Jorm, A. F., \& Reavley, N. J. (2018). Predicting Intentions to Seek Help for Depression among Undergraduates in Sri Lanka. BMC Psychiatry, 18, 122. https://doi.org/10.1186/s12888-018-1700-4

American Psychiatric Association (2013). Diagnostic and Statistical Manual of Mental Disorders, Fifth Edition: DSM-V. American Psychiatric Association.

Arafat, S. M. Y., Shams, S. F., Chowdhury, M. H. R., Chowdhury, E. Z., Hoque, M. B. et al. (2017). Adaptation and Validation of the Bangla Version of the Depression Literacy Questionnaire. Journal of Psychiatry, 20, 412. https://doi.org/10.4172/2378-5756.1000412

Bee, H. L. (2008). Lifespan Development. New York: HarperCollins.

Carpenter, W. T., Strauss, J. S., \& Bartko, J. J. (1974). The Diagnosis and Understanding of Schizophrenia. Part I. Use of Signs and Symptoms for the Identification of Schizophrenic Patients. Schizophrenia Bulletin, 11, 37-49.

https://doi.org/10.1093/schbul/1.11.37

Griffiths, K. M., Christensen, H., Jorm, A. F., Evans, K., \& Groves, C. (2004). Effect of Web-Based Depression Literacy and Cognitive-Behavioural Therapy Interventions on 
Stigmatising Attitudes to Depression: Randomised Controlled Trial. British Journal of Psychiatry the Journal of Mental Science, 185, 342.

https://doi.org/10.1192/bjp.185.4.342

Gulliver, A., Griffiths, K. M., Christensen, H., Mackinnon, A., Calear, A. L., Parsons, A. et al. (2012). Internet-Based Interventions to Promote Mental Health Help-Seeking in Elite Athletes: An Exploratory Randomized Controlled Trial. Journal of Medical Internet Research, 14, e69. https://doi.org/10.2196/jmir.1864

Hankin, B. L., Abramson, L. Y., Moffitt, T. E., Silva, P. A., Mcgee, R., \& Angell, K. E. (1998). Development of Depression from Preadolescence to Young Adulthood: Emerging Gender Differences in a 10-Year Longitudinal Study. Journal of Abnormal Psychology, 107, 128-140. https://doi.org/10.1037/0021-843X.107.1.128

Huang, X. T., Zheng, Y., Luo, M. C., Su, D., \& Chen, B. Y. (2011). Investigation and Assessment of Chinese College Students' Mental Health Service Needs. Journal of Southwest University (Social Sciences Edition), 37, 1-5.

https://doi.org/10.3969/j.issn.1673-9841.2011.03.001

Jeong, Y. M., Hughes, T. L., Mccreary, L., Johnson, T. P., Park, C., \& Choi, H. (2017). Validation of the Korean Parental Depression Literacy Scale. International Journal of Mental Health Nursing, 27, 712-726. https://doi.org/10.1111/inm.12358

Kiropoulos, L. A., Griffiths, K. M., \& Blashki, G. (2011). Effects of a Multilingual Information Website Intervention on the Levels of Depression Literacy and Depression-Related Stigma in Greek-Born and Italian-Born Immigrants Living in Australia: A Randomized Controlled Trial. Journal of Medical Internet Research, 13, e34. https://doi.org/10.2196/jmir.1527

National Comorbidity Survey-R. (2007). Lifetime Prevalence of DSM-IV/WMH-CIDI Disorders by Sex and Cohort. https://www.hcp.med.harvard.edu/ncs/ftpdir/NCS-R_Lifetime_Prevalence_Estimates.p df

Seyfi, F., Poudel, K. C., Yasuoka, J., Otsuka, K., \& Jimba, M. (2013). Intention to Seek Professional Psychological Help among College Students in Turkey: Influence of Help-Seeking Attitudes. BMC Research Notes, 6, 519.

https://doi.org/10.1186/1756-0500-6-519

Sun, Z. Q., \& Xu, Y. Y. (2014). Medical Statistics. People's Medical Publishing House.

Tabachnick, B. G., \& Fidell, L. S. (2007). Using Multivariate Statistics (5th ed.).

Wei, Y., Mcgrath, P. J., Hayden, J., \& Kutcher, S. (2016). Measurement Properties of Tools Measuring Mental Health Knowledge: A Systematic Review. BMC Psychiatry, 16, 297. https://doi.org/10.1186/s12888-016-1012-5

World Health Organization (2015). Process of Translation and Adaption of Instruments. http://www.who.int/substance_abuse/research_tools/translation/en

World Health Organization (2017). Depression: Fact Sheet. http://www.who.int/mediacentre/factsheets/fs369/en

Xu, Y., Qi, J., Yang, Y., \& Wen, X. (2016). The Contribution of Lifestyle Factors to Depressive Symptoms: A Cross-Sectional Study in Chinese College Students. Psychiatry Res, 245, 243-249. https://doi.org/10.1016/j.psychres.2016.03.009

Zhao, Q. L. (2014). Development and Application of Nursing Assessment Tools. People's Medical Publishing House. 